\title{
Self-report of Cognition and Objective Test Performance in Posttraumatic Headache
}

\author{
B. Branca, PhD; B. Giordani, PhD; T. Lutz, BA; J. R. Saper, MD
}

From the Michigan Head Pain and Neurological Institute, Ann Arbor (Drs. Branca and Saper and T. Lutz); the Department of Psychology, Eastern Michigan University, Ypailanti (Dr. Branca); and the Neuropsychology Program, Department of Psychiatry, University of Michigan, Ann Arbor (Dr. Giordani).

Address all correspondence to Dr. Barbaranne Branca, Michigan Head Pain and Neurological Institute, 3120 Professional Drive, Ann Arbor, MI 48104.

Accepted for publication September 29, 1995.

The Cognitive Difficulties Scale, a self-report measure of cognitive functioning, was administered to 111 consecutive adult referrals with posttraumatic head pain subsequent to mild to moderate head and/or cervical flexion-extension injuries who were treated at a clinic specializing in head pain and neurologicel disorders. Factor analysis of the Cognitive Difficulties Scala yielded seven meaningful factors corresponding to the type of memory inefficiencies often associated with neurological dysfunction. Further analyses comparing the Cognitive Difficulties Scale factor scores to objective tests of mental status, memory, and depressed mood demonstrated limited relationships between specific Cognitive Difficulties Scale factor scores and these measures of cognitive performance and behavior. The Cognitive Difficulties Scale appears helpful in assisting this patient population with treatment planning and specific remediation tied to everyday situations.

Key words: head injury, serf-report, depression, cognitive functioning, neuropsychology, headache

Abbreviations: CHI closed head injury, CDS Cognitive Difficulties Scale, WMS-R Wechsler Memory Scale-Revised, BDI Beck Depression Inventory, MMSE Mini-Mental State Exam, PTA posttrauroetic amnesia

(Headache 1996;36:300-306)

Subsequent to mild to moderate closed head injury $(\mathrm{CHI})$ and/or cervical flexion-extension injury, the most prevalent complaint is posttraumatic head pain ${ }^{1,2}$ along with dizziness, fatigue, depressed mood, and neurocognitive dysfunction. ${ }^{2-4}$ Posttrauma symptoms persist well beyond 6 months for many, ${ }^{5}$ with indication that headache and depression were significantly greater in the mild $\mathrm{CHI}$ than severe $\mathrm{CHI}$ population 6 months postinjury ${ }^{6}$ and headaches 2 years postinjury ${ }^{7}$ Neuropsychological evidence for cognitive and behavioral sequelae for the mild $\mathrm{CHI}$ population has been demonstrated,8-14 though the extent and persistence of these associated deficits remains unresolved. ${ }^{15,16}$ Brown et al 17 found evidence for three symptom clusters (somatic, cognitive, and affactive) which characterized mild $\mathrm{CHI}$ disturbances, persisted over time, and interfered with quality of life. On the whole, however, attempts to objectively characterize and measure by self-report in these areas have produced equivocal results. Memory has been most extensively studied, though self-report memory questionnaires have been correlated with objective measures of memory with only mixed results. ${ }^{18}$

Sunderland et al ${ }^{19}$ did find a correlation between memory test performance and subjective complaints in two head-injured groups. In working with healthy elderly patients, Larrabee and Levin ${ }^{20}$ reported a significant association between remote memory complaints and impairment on objective tests of remote memory. In a similar population, Sunderland and coworkers ${ }^{21}$ found a modest correlation between story recall performance and a subjective memory assessment measure, though word list and pattern recognition recall measures did not correlate.

Correlations between subjective and objective memory measures may be confounded by mood states, especially depression and anxiety. Kahn and associates ${ }^{22}$ found that self-report of memory dysfunction was correlated with depression, rather than with performance on objective memory measures. Broadbent et al23 also reported that self-report of cognitive efficiency was related to anxiety, stress, and depressed mood state rather than with memory testing performance. Two groups have found that, although self-ratings of memory functions were significantly related to objective memory performance, correlations between self-rating and mood states were stronger. ${ }^{20,24}$ Reports in this area are hardly consistent. West and coworkers ${ }^{25}$ reported no relationship between memory test performance and self-ratings of either mood states or cognitive ability, though the latter correlated significantly. Scogin et al, 25 however, found no sig- 
nificant relationships among memory test performance, self-evaluation of memory functioning, and self-rating of depression.

The item content of memory self-report measures also appears to be an important factor when comparing results of subjective and objective memory evaluation, or what Hermann ${ }^{18}$ terms poor "isomorphic question-to-task" fit between laboratory tasks and questionnaires. Bennett-Levy and associates 27 initially found that laboratory tasks and self-report of memory complaints had low correlation, but when items focused on what the authors termed "real life" memory skills, there were significantly higher correlations between subjective and objective measurement techniques. The underlying factor structure of a self-report measure may influence the questionnaire's association to performance on specific memory tests. Larrabee and Levin, 20 for example, found that a direct relationship between self-report of memory complaint and objective memory performance was only evident for self-report items and test variables directly related to remote memory.

McNair and Kahn²8 developed the Cognitive Difficulties Scale (CDS), a clinically relevant self-report measure of "everyday" cognitive and memory complaints. They demonstrated that CDS total scores significantly differentiated groups of normal controls administered anticholinergics of different strength. The authors also noted that "a priori" factors could be formed (ie, Attention/Concentration, Psychomotor Coordination, Orientation, Recent Memory-Verbal, Recent Memory-Visual, Long-term Memory), but did not report formal results of item factor analysis.

This study examines the factor structure of the CDS in a group of posttraumatic head pain patients. Reliance on the global CDS score, alone, was felt to yield limited information in clinical practice, and it was expected that the resultant factor scores from the CDS would lead to a clearer characterization of self-perceived cognitive deficits and the components of memory. Resultant factors were then compared to patients' performance on components of the Wechsler Memory Scale-Revised (WMS-R) 29 The interrelationship of affective and mental status to the results of both the CDS and WMS-R was also evaluated with the Beck Depression Inventory (BDI)30 and the Mini-Mental Status Examination (MMSE). ${ }^{31}$

\section{METHODS}

Subjects were 111 consecutive adult referrals with posttraumatic heed injury syndrome subsequent to mild to moderate head injury, complaining of memory dysfunction and treated at a CARF-accredited private clinic specializing in head, neck, and shoulder pain and neurological disorders. Patients were 15 to 67 years of age (mean 38.22, SD 11.37) with an education range of 8 to 19 years (mean 13.26, SD 2.37) and were evaluated from 1 to 192 months since the time of their injury (mean 31.60, SD 32.27). Estimates of posttraumatic amnesia (PTA) based on patient report placed most patients within a mild range of severity (64\% reported no PTA, $27 \%$ less than 1 hour, $5 \% 1$ to 24 hours, $4 \%$ longer than 24 hours). Of the total sample, $49 \%$ reported no loss of consciousness. Information was available on the litigation status of 103 patients, with 52 in active and unresolved litigation.

As part of all patients' routine diagnostic evaluation, they were administered the CDS, ${ }^{28}$ a 39 -item self-report measure of memory and general cognitive complaint utilizing a Likert-type scaling. Along with a complete neurological examination, patients were also administered the BDI and the MMSE. Patients had further neurodiagnostic studies, if warranted, on this day. Those with self-report of memory dysfunction were referred to the neuropsychology service and further evaluated via a semistructured interview. Patients were administered the WMS-R if they were judged to have significant cognitive complaints based on this interview. The MMSE was instituted as a screening measure after the start of the study and was not administered to the first 26 subjects.

\section{RESULTS}

Factor Analysis of CDS Items.-All subjects were included in the initial factor analysis of the CDS. Principal components factor analysis with Varimax transformation resulted in eight factors with eigenvalues greater than 1.0, accounting for $72 \%$ of the variance. Seven primary domains or factors, here named "CDS subscales," were interpreted. The last factor included only one item and was not considered viable. Four CDS items did not have a factor loading of 0.40 or greater on any of the factors and were not used in the final Total Score. Three items loaded on two factors each. Table 1 lists the items by item number, grouped into factors (ie, CDS subscales), with factor loadings for each item.

Thirteen items formed the first CDS subscale (Distractibility) with the common theme of impaired concentration and interfering distractibility. Representative items included: "When interrupted while reading, I have trouble finding my place again," and "I find it hard to keep my mind on a task or job." The second CDS subscale (ADL) consisted of nine items dealing with effectiveness in activities of daily living. For example, "I misplaced my clothing." The third CDS subscale (Prospective Memory) contained four items related to prospective memory or remembering what one has to do at a future date (eg, "I forget appointments, dates, classes"). CDS subscale 4 (Orientation) consisted of three items interpreted as current mental status or orientation (eg, "I forget the date of the month"). The fifth CDS subscale (Language) contained four items relevant to language production and fluency difficulty (eg, "I have trouble thinking of the names of objects"). The sixth CDS subscale (Fine Motor) comprised items related to fine mo- 
Table 1.-Principal Components Factor Analysis With Varimax Transformation of Individual Cognitive Difficulties Scab (CDS) Items

CDS Items

\begin{tabular}{|c|c|c|c|c|c|c|c|}
\hline \multirow[t]{2}{*}{ 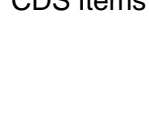 } & & & & & & & \\
\hline & $\begin{array}{c}\text { Factor I } \\
\text { Distractibility }\end{array}$ & $\begin{array}{c}\text { Factor II } \\
\text { ADL }\end{array}$ & $\begin{array}{c}\text { Factor III } \\
\text { Prospective } \\
\text { Memory }\end{array}$ & $\begin{array}{l}\text { Factor IV } \\
\text { Orientation }\end{array}$ & $\begin{array}{c}\text { Factor V } \\
\text { Language }\end{array}$ & $\begin{array}{l}\text { Factor VI } \\
\text { Fine Motor }\end{array}$ & $\begin{array}{c}\text { Factor VII } \\
\text { Long-term } \\
\text { Memory } \\
.6874\end{array}$ \\
\hline CDS2 & & & & & & & \\
\hline CDS3 & & & & & & & \\
\hline CDS4 & & & .7996 & & & & \\
\hline CDS5 & & & .9115 & & & & \\
\hline CDS6 & & & .6984 & & & & \\
\hline CDS7 & & .6380 & & & & & \\
\hline CDS8 & & & .5801 & & & & \\
\hline CDS9 & & & & & & & .8179 \\
\hline CDS10 & .9106 & & & & & & \\
\hline CDS11 & & & & & & & \\
\hline CDS12 & & & & & .9313 & & \\
\hline CDS13 & & .5133 & & & & & .5844 \\
\hline CDS14 & & & & & 1.0535 & & \\
\hline CDS15 & & & & & .5038 & & \\
\hline CDS16 & .6046 & & & & & & \\
\hline CDS17 & .4634 & & & & & & \\
\hline CDS18 & & & & & & & .4195 \\
\hline CDS19 & .7651 & & & & & & \\
\hline CDS20 & & & & & & & \\
\hline CDS21 & & & & .8234 & & & \\
\hline CDS22 & & .8691 & & & & & \\
\hline CDS23 & & & & & & & \\
\hline CDS24 & .4430 & & & & & .4342 & \\
\hline CDS25 & 1.1443 & & & & & & \\
\hline CDS26 & .6467 & & & & & & \\
\hline CDS27 & & .4687 & & & & & \\
\hline CDS28 & .9286 & & & & & & \\
\hline CDS29 & & .4216 & & & & & \\
\hline CDS30 & & & & & & .7868 & \\
\hline CDS31 & .8923 & & & & & & \\
\hline CDS32 & .4432 & & & & & & \\
\hline CDS33 & & & & & & & \\
\hline CDS34 & & .4195 & & & & & \\
\hline CDS35 & & & & & & & \\
\hline CDS36 & & & & .5458 & & & \\
\hline CDS37 & .443 & & & & & & \\
\hline CDS38 & .4445 & & & .5641 & & & \\
\hline CDS39 & & .7064 & & & & & \\
\hline
\end{tabular}

tor skills (eg, "I have trouble sewing or mending"). Long-term memory was interpreted to be represented by the four items in CDS subscale 7 (eg, "I have trouble recalling the names of people I know"). A repeated measures analysis of variance using all subjects and average CDS subscales (ie, total subscale score divided by number of items in subscale) as dependent variables was significant $[F=78.54, P<.0001]$. Post hoc comparisons revealed significant differences between all subscale comparisons. Means and standard deviations were as follows: Distractibility $1.50 \pm 0.52$, ADL $0.58 \pm 0.46$, Prospective Memory $1.79 \pm 0.66$, Orientation $1.17 \pm 0.63$, Language $1.63 \pm 1.01$, Fine Motor $0.91 \pm 0.67$, and Long-term Memory $1.3 \pm 0.69$. Lowest scores (least complaint) were noted for the ADL and Fine Motor factors, while the highest scores were noted for Prospective Memory, Language, and Distractibility.

Relationship of CDS Scores With Other Study Variables. -The total CDS score for the 111 subjects correlated above the $P<.001$ level with each individual item score (correlation range $=.55-90$ ). Correlations among the seven CDS subscales were reasonable, with the lowest correlation between the Fine Motor subscale and the others, particularly Prospective Memory (Table 2). The BDI was significantly correlated with the total CDS score and four of the seven CDS subscales, with significance not being reached for Language, Fine Motor, or Long-term Memory (Table 3). Using Student's $t$-test, a comparison for gender on the CDS subscales and total scores demonstrated no significant differences. Cognitive Difficulties Scale scores also did not correlate with months since injury. Education was not significantly related to any of the CDS subscale scores, though age was significantly related to the Long-term Memory rating $(r=.31, P<.001)$. 
Table 2.- Correlations Among Cognitive Difficulties Scale (CDS) Subscales

\begin{tabular}{|c|c|c|c|c|c|c|c|}
\hline \multirow[b]{2}{*}{ Total } & & & & Prospectiv & & & \\
\hline & Tulal & Distiactiomi & ALL & Memory & Odentation & Language & FIne IMlotor \\
\hline Distraction & $.90^{*}$ & & & & & & \\
\hline ADL & $.80^{*}$ & .56 & & & & & \\
\hline $\begin{array}{l}\text { *Prospective } \\
\text { Memory }\end{array}$ & $.70^{\star}$ & $.54^{*}$ & $.53^{*}$ & & & & \\
\hline Orientation & $.76^{\star}$ & $.62^{\star}$ & $.53^{*}$ & $.48^{\star}$ & & & \\
\hline Language & $.72^{\star}$ & $.63^{\star}$ & $.54^{*}$ & $.44^{\star}$ & $.51^{*}$ & & \\
\hline Fine Motor & $.55^{\star}$ & $.49^{\star}$ & $.44^{*}$ & $.18^{\star}$ & $.41^{*}$ & $.33^{*}$ & \\
\hline $\begin{array}{l}\text { Long-term } \\
\text { Memory } \\
{ }^{*} \mathrm{P}<.001 \\
{ }^{\star \star} \mathrm{P}<-05\end{array}$ & $.74^{*}$ & $.56^{*}$ & $.60^{*}$ & $.52^{*}$ & $.48^{*}$ & $.56^{*}$ & $.36^{*}$ \\
\hline
\end{tabular}

Table 3.-Correlations Between Cognitive Difficulties Scale (CDS) and Other Select Variables

\begin{tabular}{|c|c|c|c|c|c|c|c|c|}
\hline Prospective & Total & Distraction & $A D L$ & Memory & Orientation & Language & $\begin{array}{l}\text { Fine } \\
\text { Motor }\end{array}$ & $\begin{array}{l}\text { Long-term } \\
\text { Memory }\end{array}$ \\
\hline \multicolumn{9}{|l|}{$\begin{array}{l}\text { WMS-R } \\
\text { Subscales }\end{array}$} \\
\hline Verbal & $-.28^{\star}$ & $-.30^{\star}$ & -.15 & -.22 & -.23 & $-.25^{\star}$ & -.03 & -.07 \\
\hline Visual & $-.35^{\star *}$ & $-.44^{* * *}$ & -.20 & -.18 & -.16 & -.19 & -.12 & -.19 \\
\hline General & $-.31^{*}$ & $-.35^{\star \star}$ & -.17 & $-.24^{*}$ & -.21 & $-.25^{\star}$ & -.05 & -.11 \\
\hline $\begin{array}{l}\text { Attention/ } \\
\text { Concentrati } \\
\text { on }\end{array}$ & -.19 & -.20 & -.18 & -.02 & -.15 & -.17 & -.05 & -.03 \\
\hline $\begin{array}{l}\text { Delayed } \\
\text { Recall }\end{array}$ & $-.28^{\star}$ & $-.32^{*}$ & -.17 & $-.27^{\star}$ & -.18 & -.22 & -.05 & -.09 \\
\hline $\begin{array}{l}\text { MMSE } \\
\text { BDI } \\
{ }^{*} P>05 \\
{ }^{* *} P<.01 . \\
{ }^{* * *} P<.001 .\end{array}$ & $\begin{array}{l}-.25^{\prime *} \\
.35^{\star * *}\end{array}$ & $\begin{array}{l}-.19^{\star} \\
.35^{\star \star *}\end{array}$ & $\begin{array}{l}-.17 \\
.29^{* *}\end{array}$ & $\begin{array}{l}-.10 \\
.24^{*}\end{array}$ & $\begin{array}{l}-.26^{*} \\
.21^{*}\end{array}$ & $\begin{array}{c}-.28^{*} \\
.19\end{array}$ & $\begin{array}{c}-.22 \\
.14\end{array}$ & $\begin{array}{c}-.25^{\star} \\
.12\end{array}$ \\
\hline
\end{tabular}

Significant correlations were noted between a number of WMS-R indices and CDS subscales using the smaller sample of patients who had completed all of these tests (Table 3). The CDS Distractibility subscale correlated with each WMS-R Memory Index and the WMS-R General Memory Index, as well as specific correlations being found between the CDS Language subscale and WMS-R Verbal Memory Index and the CDS Prospective Memory subscale and the WMS-R Delayed Recall Index. Beck Depression Inventory scores correlated with the CDS Total Score and with all individual subtest scores with the exception of Language, Fine Motor, and Long-term Memory.

Headache level was not significantly correlated with scores from the WMS-R, BDI, MMSE, or CDS, When patients were divided as to their neurological examination or EEG results (ie, normal, abnormal), headache level was similar in both groups. Patients actively involved in litigation, when compared to those not in litigation, were found to report greater difficulty on the ADL, Orientation, and Distractibility subscales of the CDS (Table 4). This group also had a higher mean Beck depression score and reported greater severity of headache. Of the smaller sample of patients who completed the MMSE and WMS-R, no differences were found on these measures between those in litigation and those not actively involved.

Factor Analysis of CDS Factors to Memory Testing and BDI.-In order to more closely address the relationship between the CDS subscale scores and patients' objective test performance, the scores from the MMSE, the WMR-S subtests, individual CDS subscales, and the BDI were submitted to a principal components analysis with varimax rotation for the 50 patients who had completed all three measures. The factor analysis resulted in seven factors with eigenvalues of 1.0 or greater, which together explained $76 \%$ of the variance.

Six subscales from the CDS fell on Factor I (Table 5). Factors III and V were exclusive to the WMS-R 
Table 4.-Comparison of Cognitive Difficulties Scale (CDS), Beck Depression Inventory (BDI), and Headache Level Scores for Patients in Litigation and Patients Not Involved in Litigation

\begin{tabular}{lccc}
\multicolumn{1}{c}{ Variable } & $\begin{array}{c}\text { No } \\
(\mathrm{n}=52)\end{array}$ & $\begin{array}{c}\text { Litigation } \\
(\mathrm{n}=51)\end{array}$ & $P$ \\
$\mathrm{ADL}$ & .69 & .48 & $\mathrm{NS}$ \\
Prospective Memory & 1.9 & 1.7 & $<.01$ \\
Orientation & 1.3 & 1.0 & $\mathrm{NS}$ \\
Language & 1.7 & 1.5 & $\mathrm{NS}$ \\
Fine Motor & 1.0 & .81 & $\mathrm{~N}$ \\
Long-term Memory & 1.3 & 1.3 & $<.003$ \\
Distractibility & 1.6 & 1.4 & $<.003$ \\
Total & 61.5 & 49.6 & $<.007$ \\
BDI & 68.8 & 56.7 & $<.05$
\end{tabular}

Patients with completed litigation or for whom status was unclear were not included due to their small number.

subtests of digit span and visual span. The MMSE loaded exclusively on Factor VI. The BDI loaded with both of the Logical Memory subtests of the WMS-R on Factor II, and the CDS Fine Motor sub-scale loaded with the WMS-R Visual Recall sub-test on Factor IV. The CDS Prospective Memory was found to be associated with delayed recall of visual stimuli (WMS-R Visual Recall II) on Factor VII.

\section{COMMENTS}

The results of this study indicate that a self-report questionnaire of memory functioning can be factor analyzed into meaningful components. The seven primary domains of Distractibility, Activities of Daily Living, Prospective Memory, Orientation, Language, Fine Motor, and Long-term Memory correspond to the types of memory inefficiencies often associated with neurological dysfunction. Responses to CDS items did not appear to be affected by patients' age or education, with the exception of Long-term Memory that correlated significantly with age. This subscale may be sensitive to expected age-related declines in memory and recall. The fact that CDS scores did not correlate with time since injury may reflect the chronic nature of this patient population's cognitive complaints as they continue to seek care some time after their injury.

Differences among the CDS subscale means also reflect expected qualitative distinctions in posttraumatic patients' complaints, with the highest scores coming on memory and attention-related sub-scales, including the Language subscale with its emphasis on word-finding problems. The lowest scores on subscales reflecting motor skills and adaptive tasks would not be expected to be high in a community dwelling population with an average of 31 months since their injury. Four of the a priori item clusters suggested by McNair and Kahn ${ }^{28}$ corresponded well to results of the present

Table 5.-Principal Components Factor Analysis With Varimax Transformation for Cognitive Difficulties Scale (CDS) Subscales end Measures of Memory, Mental Status, and Mood

CDS Subscales

Distraction

ADL

Prospective Memory

Orientation

Language

Fine Mortor

Long-term Memory
II

III

Factors

$\begin{array}{llll}\text { IV } & \text { V } & \text { VI }\end{array}$

.70

.82

.86

.64

.58

.64

WMS-R Scores

Digit Span Forward

Digit Span Backward

Visual Memory Span Forward

Visual Memory Span Backward

Logical Memory I

Logical Memory II

Visual Recall I

Visual Recall II

BDI

MMSE

-.62

.51

.90

89

.80

.86 
factor analysis (ie, attention/concentration to Distractibility; psychomotor coordination to Fine Motor; orientation to Orientation; long-term memory to Long-term Memory). McNair and Kahn ${ }^{28}$ also described having selected items for the CDS that would represent verbal and visual recent memory, though distinct factors related to these domains were not found in this study.

The correlations between the CDS total score and specific subscale scores (eg, Distractibility, Prospective Memory, Language) and the WMS-R summary indices (eg, General Memory, Verbal Memory, etc), although modest at best, did demonstrate limited relationships between subjective and objective measures of memory performance in this restricted population. Consistent with this, Gfeller et al32 found that self-report of persistent postconcussion complaints and impairment on neuropsychological tests were positively correlated. The CDS, ADL, Orientation, and Long-term Memory subscale scores did not demonstrate significant correlations with the WMS-R indices, as might be expected given the nature of the individual items making up those subscales. For example, the items in the Long-term Memory subscale predominantly relate to difficulties with well learned everyday abilities, such as recognizing faces of familiar persons. Although the Attention/Concentration index of the WMS-R did not correlate significantly with any of the CDS subscales, the highest correlation was found with CDS Distractibility.

When the individual CDS subscale scores were included in a factor analysis with the WMS-R individual subtests, the MMSE, and the BDI, the Prospective Memory subscale of the CDS appeared together on the same factor with the Visual Delayed Recall subtest of the WMS-R, suggesting at least a basic relationship between objective and subjective measures of learning ability. Objective measures of verbal recall, rather than CDS subscales were found to be associated with self-report of depressed mood. This differs somewhat from the findings of Larrabee and Levin ${ }^{20}$ who found not only a relationship in the elderly between Zung depression scale scores and attention and concentration measures, but also with subscales on the 18-item Squire et al ${ }^{33}$ self-rating of memory scale. Further research will be needed to evaluate the differences between Larrabee and Levin's finding and our results, as the studies differed not only on test measures, but also with respect to study populations. Visual Reproduction I from the WMS-R and the CDS factor score of Fine Motor Control also fell on a single factor. Although unexpected, this could reflect the importance of motor control and graphic quality in contributing to the accuracy score for Reproduction I.

Consistent with the findings of Tsushima and Tsushima, ${ }^{34}$ headache level in our study did not relate to objective test scores for cognitive performance and mental status. Further, we found no relationship between headache activity and subjective report of memory and cognitive difficulties using the CDS. For the purposes of this study, we divided our patients into two groups depending on whether they were actively involved in litigation. Although this could be considered a crude measure and reliant only on self-report, we did find that patients differed in several subscales of the CDS (ie, ADL, Orientation, Distractibility). Headache activity and depression were also significantly higher in the litigation group. Interestingly, self-report by CDS Long-term Memory and Prospective Memory subscales, as well as objective memory performance on the WMS-R, did not differ between the two patient groups. It is possible that the differences noted on the significant CDS subscales may have related to symptoms consistent with their higher report of depression and headache complaints. Across all the patients in this study, however, headache level did not relate to any of the objective or subjective measures of cognitive status. Beck Depression Inventory scores, on the other hand, did significantly correlate with several of the CDS subscales found to differ between the litigation and nonlitigation groups, suggesting the need for careful assessment of mood in medicolegal situations.

Posttraumatic patients often do not adequately perceive the significant changes that may have occurred in their cognitive ability level following their injury. As a consequence, they may choose a level of work or make significant interpersonal or economic decisions that are not appropriate, leading to the potential for marked social or home disruption. ${ }^{35}$ The CDS would appear to be a helpful tool in treatment planning with posttraumatic patients, as it allows for a client-centered discussion of specific cognitive and primarily memory-based complaints tied to everyday-type settings that can then be targeted for specific remediation.

\section{REFERENCES}

1. Cartlidge NEF, Shaw DA, with a contribution by Kalbag RM. Post-traumatic headache. Major Probl Neurol Head Inj. 1981;10:95-115.

2. Rimel RW, Giordani B, Barth JT, Boll TJ, Jane JA. Disability caused by minor head injury. Neurosurgery. 1981;9:221-228.

3. Lidvall HF, Linderoth B, Norlin B. Causes of the post-concussional syndrome. Acta Neurol Scand Suppl. 1974;56:3-144.

4. Alves WM, Colohan A, O'Leary TJ. Understanding post-traumatic symptoms after minor head injury. $J$ Head Trauma Rehab. 1986;1:1-12. 
5. Bohnen N, Twijnstra A, Jolles J. Post-traumatic and emotional symptoms in different subgroups of patients with mild head injury. Brain Inj. 1992;6:481-487.

6. Alexander MP. Neuropsychiatric correlates of persistent postconcussive syndrome. J Head Trauma Rehab. 1992;7:60-69.

7. Uomoto JM, Esselman PC. Traumatic brain injury and chronic pain: differential types and rates by head injury severity. Arch Phys Med Rehabil. 1993;74:61-64.

8. Hugenholtz H, Stuss DT, Stethem LL, Richard MT. How long does it take to recover from a mild concussion? Neurosurgery. 1988;22:853-858.

9. MacFlynn G, Montgomery EA, Fenton GW, Rutherford W. Measurement of reaction time following minor head injury. J Neurol Neurosurg Psychiatry. 1984;47:1326-1331.

10. Gronwall D, Wrightson P. Delayed recovery of intellectual function after minor head injury. Lancet. 1974;2:605-609.

11. Gronwall D, Wrightson P. Memory and information processing capacity after closed head injury. $J$ Neurol Neurosurg Psychiatry. 1981;44:889-895.

12. Barth JT, Macciocchi SN, Giordani B, Rimel R, Jane JA, Boll TJ. Neuropsychological sequelae of minor head injury. Neurosurgery. 1983;13:529-533.

13. Bohnen N, Jolles J, Twijnstra A. Neuropsychological deficits in patients with persistent symptoms six months after mild head injury. Neurosurgery. 1992;30:692-696.

14. Ewing R, McCarty D, Gronwall D. Persisting effects of minor head injury observable during hypoxic stress. $J$ Clin Neurophysiol. 1980;2:147-155.

15. Ruff RM, Levin HS, Mattis S, et al. Recovery of memory after mild head injury: a three-center study. In: Levin HS, Elsenberg HM, Benton AL, eds. Mild Head Injury. New York: Oxford University Press; 1989.

16. Dikmen S, McLean A, Tamkin N. Neuropsychological and psychosocial consequences of minor head injury. J Neurol Neurosurg Psychiatry. 1986;49:1227-1232.

17. Brown SJ, Fann JR, Grant I. Postconcussional disorder: time to acknowledge a common source of neurobehavioral morbidity. J Neuropsychiatry Clin Neurosci. 1994;6:15-22.

18. Hermann D. Knowthy memory: the use of questionnaires to assess and study memory. Psychol Bull. 1981;92:434-452.

19. Sunderland A, Harris J, Baddeley A. Do laboratory tests predict everyday memory? A neuropsychological study. J Verb Learn Verb Behav. 1979;22:341-57.

20. Larrabee GJ, Levin HS. Memory self-ratings and objective test performance in a normal elderly sample. $J$ Clin Exp Neuropsychol. 1986;8:275-284.

21. Sunderland $A$, Watts $K$, Baddeley AD, Harris JE. Subjective memory assessment and test performance in elderly adults. J Gerontol. 1986;41:376-384.

22. Kahn RL, Zarit SH, Hilbert NM, Niederehe G. Memory complaint and impairment in the aged. The effect of depression and altered brain function. Arch Gen Psychiatry. 1975;32:1569-1573.

23. Broadbent DE, Cooper PF, FitzGerald P, Parkes KR. The Cognitive Failures Questionnaire (CFQ) and its correlates. Br J Clin Psychol. 1982;21:1-16.

24. Schacter DL, Crovitz HF. Memory function after closed head injury: a review of the quantitative research. Cortex. 1977;13:150-176.

25. West RL, Boatwright LK, Schleser R. The link between memory performance, self-assessment, and affective status. Exp Aging Res. 1984;10:197-200.

26. Scogin F, Storandt M, Lott L. Memory-skills training, memory complaints, and depression in older adults. J Gerontol. 1985;40:562-568.

27. Bennett-Levy J, Polkey CE, Powell GE. Self-report of memory skills after temporal lobectomy: the effect of clinical variables. Cortex. 1980;16:543-557.

28. McNair D, Kahn R. Self-assessment of cognitive deficits. In: Crook T, Ferris S, Bartus R, eds. Assessment in Geriatric Psychopharmacology. New Canaan, Conn: Mark Powley and Associates; 1983:137-143.

29. Wechsler D. WMS-R: Wechsler Memory Scale - Revised, Manual. New York: The Psychological Corporation; 1987.

30. Beck AT. The Diagnosis and Management of Depression. Philadelphia: University of Pennsylvania; 1973.

31. Folstein MF, Folstein SE, McHugh PR. "Mini-mental state." A practical method for grading the cognitive state of patients for the clinician. J Psychiatr Res. 1975;12:189-198.

32. Gfeller JD, Chibnall JT, Duckro PN. Postconcussion symptoms and cognitive functioning in posttraumatic headache patients. Headache. 1994;34:503-507.

33. Squire LR, Wetzel CD, Slater PC. Memory complaint after electroconvulsive therapy: assessment with a new self-rating instrument. Biol Psychiatry. 1979;14:791-801.

34. Tsushima WT, Tsushima VG. Relation between headaches and neuropsychological functioning among head injury patients. Headache. 1993;33:139-142.

35. Prigatano GP, Disturbances of self-awareness of deficit after traumatic brain injury. In: Prigatano GP, Schacter DL, eds. Awareness of Deficit After Brain Injury. New York: Oxford University Press; 1991. 